\title{
BUSCANDO UM BIOHERBICIDA CONTRA Cyperus sp (tiririca)
}

\section{CRISTINE B. GONZALEZ ${ }^{1}$ e IRACEMA O. MORAES ${ }^{2}$}

${ }^{1}$ UNITINS/Faculdade de Agronomia - Campus Gurupi. TOCANTINS . UNESP/IQ Araraquara/Pós-Graduação em Biotecnologia, Brasil. cristine@naves.com.br

${ }^{2} \mathrm{CEA} / \mathrm{UNESP} / \mathrm{RIO}$ CLARO. DETA/IBILCE/UNESP/SJRP. IQ/UNESP/Araraquara. Coordenação de Engenharia Química, Universidade Guarulhos, Guarulhos, SP, Brasil. iomoraes@hotmail.com

\section{RESUMO}

Como alternativa ao controle convencional do Cyperus sp (tiririca) usando produtos químicos, surge o controle biológico, empregando-se microrganismos fitopatógenos. Como resultados da produção massal de Cercospora henningsii e Cercospora caricis através de cultivo submerso em meio de cultura batata-dextrose (BD), observou-se que ambas espécies obtiveram um crescimento ótimo a $36^{\circ} \mathrm{C}$, sendo que para $C$. henningsii se deu com $72 \mathrm{~h}$ de fermentação e para $C$. caricis com $60 \mathrm{~h}$. Os experimentos de campo, bem como os de Câmara úmida, contra Cyperus sp (tiririca), com os produtos obtidos pelo cultivo submerso de Cercospora sp (C. henningsii e/ou $C$. caribaea), demonstraram a patogenicidade, ou seja, o potencial bioherbicida desses microrganismos.

Palavras-chave: fermentação submersa, controle biológico, erva daninha, tiririca, bioherbicida.

\section{ABSTRACT}

As an alternative to conventional control of Cyperus sp (herbaceous nutsedge), with chemical products, it rises the biological control, making use of phytopathogenic microorganisms. As results of the whole production of Cercospora henningsii e Cercospora caricis by fermentation in potato-dextrose (PD) liquid medium, it was observed that both species obtained the optimum growth at $36^{\circ} \mathrm{C}$. C. henningsii 
attained the best value after a period of $72 \mathrm{~h}$ of fermentation and C. caricis attained it after $60 \mathrm{~h}$. The field experiments, against Cyperus sp (nutsedge), with the obtained products by liquid fermentation of Cercospora sp (C. henningsii and/or C. caribaea), and with the use of "wet chamber", proved the pathogenic potential bioherbicide of these microorganisms.

Keywords: Cyperus sp, Cercospora sp, bioherbicide, fermentation, phytopathogen

\section{INTRODUÇÃO}

A família Cyperaceae inclui aproximadamente 3.000 espécies, das quais cerca de 220 espécies são identificadas como ervas daninhas. Destas, $42 \%$ pertencem ao gênero Cyperus (BENDIXEN \& NANDIHALLI 1987). Segundo JOLY (1975) Cyperus sp (tiririca) é conhecida mundialmente como uma das maiores pragas de jardins, com larga distribuição, sendo que no Brasil, sua ocorrência é generalizada em praticamente todos os estados e territórios.

Cyperus rotundus (tiririca comum ou tiririca verdadeira) é conhecido em inglês pela denominação de "purple nutsedge". Segundo LORENZI (1991), a erradicação desta planta no Brasil deveria ser considerada como "problema de segurança nacional".

Conforme BARRETO \& EVANS (1995), C. rotundus é nativa do velho mundo, mas seu centro de origem ainda é incerto.

Segundo FUSTAÍNO \& ORSI (1997), a tiririca Cyperus rotundus, é classificada como uma das ervas daninhas mais problemáticas. Estimam os autores, que haja uma perda média de $40 \%$ na produção de cana de açúcar das áreas infestadas, ou seja, aproximadamente um milhão de hectares no Brasil.

Como um método alternativo de controle de ervas daninhas, surge o controle biológico empregando-se microrganismos fitopatogênicos.

O controle biológico de plantas daninhas oferece vantagens sobre o controle com herbicidas químicos, segundo EVANS (1986).

O estudo do emprego de patógenos microbianos contra plantas daninhas, data da década de sessenta, embora o conceito seja quase tão antigo quanto a ciência de patologia de plantas, segundo WILSON (1969).

Nos últimos vinte anos o assunto experimentou alguma evolução, conforme TEMPLETON et al. (1979), HANSAN (1980), TEBEEST \& TEMPLETON (1985), EVANS (1986) e MORAES et al. (1991), especialmente motivados pelos problemas ambientais existentes e predizíveis, resultantes da contínua aplicação de pesticidas 
químicos.

O potencial de alguns fungos herbipatógenos tem sido avaliado, baseado em observações de campo (CASTELLANI 1942, PHATAK et al. 1983, FREEMAN \& CHARUDATTAN 1984, BARRETO \& EVANS 1995, WETZSTEIN \& PHATAK 1987, STOVALL \& CLAY 1988, UPADHAYAY \& STROBEL et al. 1990, CHARUDATTAN 1991; UPADHAYAY et al. 1991, TEBEEST et al. 1992, BORGES NETO 1997 e RIBEIRO et al. 1997).

BARRETO \& EVANS (1995) afirmaram terem sido os primeiros a registrar Cercospora caricis Ouden em plantas de tiririca (Cyperus rotundus), no Brasil. Verificaram sua ocorrência durante todo o ano no estado do Rio de Janeiro, Brasil e ainda que, esta espécie é um patógeno muito prejudicial ao $C$. rotundus. Um isolado de $C$. caricis Ouden foi encontrado causando sérios danos em $C$. rotundus, na região do Distrito Federal, Brasil (RIBEIRO et al. 1997). Este microrganismo é considerado um agente potencial para o biocontrole de Cyperus sp, embora a produção de esporos in vitro seja limitada (BARRETO \& EVANS, 1995, BORGES NETO, 1997 e RIBEIRO et al. 1997).

GONZALEZ, 1998 estudou o processo fermentativo de obtenção de um bioherbicida. Utilizou microrganismos existentes em coleção de cultivo do país e substratos de baixo custo e grande disponibilidade. O produto obtido pela fermentação foi testado com relação a inibição de desenvolvimento de Cyperus sp (tiririca). Este trabalho foi conduzido utilizando Cercospora caricis, Cercospora caribae e Cercospora henningsii.

\section{MATERIAL E MÉTODOS}

Utilizou-se Cercospora caribaea-2749 (A), C. henningsii-2751(B) obtidos da Coleção de Cultivos do Departamento de Micologia, Centro de Ciências Biológicas da Universidade Federal de Pernambuco, PE, Brasil e C. caricis (CEN142)(F), cedido por Mello, S. C. M. (CENARGEN/Embrapa, Brasília, DF, Brasil). Este microrganismo foi isolado de $C$. rotundus, no Distrito Federal, Brasil em Março/1996 (BORGES NETO 1997). Essas três linhagens de fungos foram mantidas em meio BDA (batata dextrose ágar) e repicadas quando necessário.

O processo fermentativo e o preparo do inóculo foram realizados com meio líquido BD (batata-dextrose), preparado na proporção de $200 \mathrm{~g}$ de refugo de batata inglesa e $20 \mathrm{~g}$ de dextrose/L de água destilada, sendo utilizados frascos de Erlenmeyer de $250 \mathrm{ml}$, contendo $100 \mathrm{ml}$ do meio de cultura. $\mathrm{O}$ pH foi corrigido para 6,5 pela adição de $\mathrm{NaCl}$ e logo após foram autoclavados 15 minutos a $121^{\circ} \mathrm{C}$. 
Os inóculos foram obtidos dos três microganismos mantidos em tubos de ensaio com meio ágar (BDA), dos quais foram retiradas duas alçadas (alça de platina estéril) de micélio de cada microrganismo, e respectivamente colocados nos frascos de Erlenmeyer com meio líquido estéril. Procedeu-se ao crescimento celular sob agitação em agitador rotatório a $150 \mathrm{rpm}, 30^{\circ} \mathrm{C}$, sob um regime de escuro constante, durante o período de sete dias. Após esse período estava concluida a fermentação e prontos os inóculos líquidos ( $\pm 100 \mathrm{~g}$ ) de Cercospora caribae, C. henningsii e C. caricis.

Foram avaliados temperatura e tempo de fermentação para a produção do bioherbicida, ou seja para o crescimento celular. Foram inoculadas duas alçadas de $C$. henningsii e C. caricis, provenientes dos inóculos líquidos fermentados (acima descrito) em erlenmeyers com BD, estéreis, separadamente. Esses frascos de Erlenmeyer foram colocados sob agitação de $150 \mathrm{rpm}$, sob um regime de escuro constante, em dois agitadores incubadores, com diferentes temperaturas, um com $30^{\circ} \mathrm{C}$ e o outro com $36^{\circ}$ C . Para cada temperatura, cada linhagem foi amostrada nos seguintes períodos de crescimento: 24 h, 36 h, 48, 60 h, 72 h, 84 h e 96 h. Cada frasco de Erlenmeyer foi considerado como unidade experimental. Alguns foram submetidos à determinação, após receber o inóculo, considerados indivíduos controle (sem sofrerem processo fermentativo).

O crescimento celular foi determinado através da densidade ótica realizada em quatro comprimentos de onda $(380 \mathrm{~nm}, 500 \mathrm{~nm}, 545 \mathrm{~nm}$ e $560 \mathrm{~nm})$, utilizando-se espectrofotômetro e através da massa seca, para cada período de fermentação e para o controle.

O bioensaio foi realizado com os fungos Cercospora caribaea e $C$. henningsii, utilizando-se os produtos (bruto) do inóculo líquido fermentado, produzido para cada uma dessas duas linhagens. Os dois produtos distintos foram, cada um diluído com água destilada até completar $500 \mathrm{ml}$ de solução e foram testados no campo. Uma pequena área natural de tiririca (Cyperus sp) foi testada para cada espécie, separadamente. As suspensões dos fungos foram regadas nas plantas de tiririca. Foram feitas observações semanais por um determinado período. Para o ensaio de Câmara úmida, um exemplar ao acaso, de planta de tiririca seca, previamente regada com a suspensão de Cercospora sp ( $C$ caribaea ou $C$. henningsii), como foi descrito no bioensaio de campo, foi levada ao laboratório, onde teve suas folhas e raízes extraídas, deixando-se apenas o tubérculo com uma parte do caule. Esta porção da planta foi lavada em água destilada corrente e desinfetada em água sanitária por 7 minutos, em seguida foi colocada em uma câmara úmida para que se pudesse verificar a ocorrência de esporulação do microrganismo para a comprovação de que a planta foi efetivamente infectada pelo microrganismo. 


\section{RESULTADOS E DISCUSSÃO}

Nas TABELAS 1 e 2, pode-se observar que Cercospora henningsii (B) e $C$. caricis $(\mathrm{F})$ obtiveram um crescimento ótimo a $36^{\circ} \mathrm{C}$, sendo que para a primeira linhagem se deu com $72 \mathrm{~h}$ de crescimento e para a segunda com $60 \mathrm{~h}$. A $30^{\circ} \mathrm{C}$ houve melhor crescimento para ambas, com $84 \mathrm{~h}$ de fermentação. Para as duas temperaturas estudadas não ocorreram significativas variações nos valores obtidos, com exceção do período ótimo de crescimento a $36^{\circ} \mathrm{C}$.

Os valores de crescimento da massa micelial obtidos por esse meio de avaliação apresentaram o mesmo comportamento daqueles obtidos pela massa seca.

TABELA 1. Valores da produção de massa micelial de Cercospora henningsii (B), obtidos pela massa seca e através de densidade ótica, para os períodos de crescimento: $24 \mathrm{~h}, 36 \mathrm{~h}, 48 \mathrm{~h}, 60 \mathrm{~h}, 72 \mathrm{~h}, 84 \mathrm{~h}, 96 \mathrm{~h}$ e controle. (* Todas as amostras de $15 \mathrm{ml}$ foram diluídas a $100 \mathrm{ml}$ )

\begin{tabular}{||c||c||c||c||c||}
\hline \multicolumn{2}{|c||}{ MASSA SECA } & \multicolumn{2}{c||}{ DENSIDADE ÓTICA * } \\
\hline \hline TRATAMENTO & $\left.\mathbf{3 0}^{\mathbf{0}} \mathbf{C}\right)$ & $\left.\mathbf{3 6}^{\mathbf{0}} \mathbf{C}\right)$ & $\left.\mathbf{3 0}^{\mathbf{0}} \mathbf{C}\right)$ & $\left.\mathbf{( 3 6}^{\mathbf{0}} \mathbf{C}\right)$ \\
\hline \hline B-CONTROLE & $\begin{array}{c}21,3 \\
\mathrm{~g} / 1\end{array}$ & - & $560 \mathrm{~nm}=0,256$ & - \\
& & & $380 \mathrm{~nm}=0,375$ & \\
\hline \hline B-24H & 21,6 & - & $560 \mathrm{~nm}=0,259$ & - \\
& $\mathrm{g} / 1$ & & $380 \mathrm{~nm}=0,427$ & \\
\hline \hline B-36H & $19 \mathrm{~g} / 1$ & $25 \mathrm{~g} / 1$ & $560 \mathrm{~nm}=0,245$ & $560 \mathrm{~nm}=0,198$ \\
& & & $380 \mathrm{~nm}=0,364$ & $380 \mathrm{~nm}=0,312$ \\
\hline \hline B-48H & 23,6 & 19,6 & $560 \mathrm{~nm}=0,291$ & $560 \mathrm{~nm}=0,256$ \\
& $\mathrm{~g} / 1$ & $\mathrm{~g} / 1$ & $380 \mathrm{~nm}=0,334$ & $380 \mathrm{~nm}=0,353$ \\
\hline B-60H & 24,3 & 19,3 & $560 \mathrm{~nm}=0,344$ & $560 \mathrm{~nm}=0,393$ \\
& $\mathrm{~g} / 1$ & $\mathrm{~g} / 1$ & $380 \mathrm{~nm}=0,531$ & $380 \mathrm{~nm}=0,629$ \\
\hline \hline B-72H & 23,3 & $27 \mathrm{~g} / 1$ & $560 \mathrm{~nm}=0,293$ & $560 \mathrm{~nm}=0,633$ \\
& $\mathrm{~g} / 1$ & & $380 \mathrm{~nm}=0,383$ & $380 \mathrm{~nm}=0,880$ \\
\hline \hline B-84H & 25,6 & 23,6 & $560 \mathrm{~nm}=0,429$ & $560 \mathrm{~nm}=0,367$ \\
& & & & \\
\hline \hline
\end{tabular}




\begin{tabular}{||c||c||c||c||c||} 
& $\mathrm{g} / 1$ & $\mathrm{~g} / 1$ & $380 \mathrm{~nm}=0,570$ & $380 \mathrm{~nm}=0,491$ \\
\hline \hline B-96H & 24,3 & 25,3 & $560 \mathrm{~nm}=0,331$ & $560 \mathrm{~nm}=0,349$ \\
& $\mathrm{~g} / 1$ & $\mathrm{~g} / 1$ & & \\
& & & $380 \mathrm{~nm}=0,476$ & $380 \mathrm{~nm}=0,432$ \\
\hline
\end{tabular}

TABELA 2. Valores da produção de massa micelial de Cercospora caricis (CEN142/F), obtidos pela massa seca e através de densidade ótica, para os períodos de crescimento: $24 \mathrm{~h}, 36 \mathrm{~h}, 48 \mathrm{~h}, 60 \mathrm{~h}, 72 \mathrm{~h}, 84 \mathrm{~h}, 96 \mathrm{~h}$ e controle. (* Todas as amostras de $15 \mathrm{ml}$ foram diluídas a $100 \mathrm{ml}$ )

\begin{tabular}{|c|c|c|c|c|}
\hline \multicolumn{3}{|c|}{ MASSA SECA } & \multicolumn{2}{|c|}{ DENSIDADE ÓTICA * } \\
\hline $\begin{array}{c}\text { Períodos/ } \\
\text { crescimento: }\end{array}$ & $\left(30^{\circ} \mathrm{C}\right)$ & $\left(36^{\circ} \mathrm{C}\right)$ & $\left(30^{\circ} \mathrm{C}\right)$ & $\left(36^{\circ} \mathrm{C}\right)$ \\
\hline F-controle & $21 \mathrm{~g} / 1$ & - & $\begin{array}{l}560 \mathrm{~nm}=0,216 \\
380 \mathrm{~nm}=0,324\end{array}$ & \\
\hline F-24h & $22,3 \mathrm{~g} / 1$ & - & $\begin{array}{l}560 \mathrm{~nm}=0,216 \\
380 \mathrm{~nm}=0,324\end{array}$ & - \\
\hline F-36h & $21 \mathrm{~g} / 1$ & $20 \mathrm{~g} / 1$ & $\begin{array}{l}560 \mathrm{~nm}=0,251 \\
380 \mathrm{~nm}=0,382\end{array}$ & $\begin{array}{l}560 \mathrm{~nm}=0,250 \\
380 \mathrm{~nm}=0,470\end{array}$ \\
\hline F-48h & $24 \mathrm{~g} / 1$ & $19,3 \mathrm{~g} / 1$ & $\begin{array}{l}560 \mathrm{~nm}=0,291 \\
380 \mathrm{~nm}=0,585\end{array}$ & $\begin{array}{l}560 \mathrm{~nm}=0,311 \\
380 \mathrm{~nm}=0,480\end{array}$ \\
\hline F-60h & $22,3 \mathrm{~g} / 1$ & $35 \mathrm{~g} / 1$ & $\begin{array}{l}560 \mathrm{~nm}=0,344 \\
380 \mathrm{~nm}=0,447\end{array}$ & $\begin{array}{l}560 \mathrm{~nm}=0,696 \\
380 \mathrm{~nm}=0,823\end{array}$ \\
\hline F-72h & $19 \mathrm{~g} / 1$ & $23,6 \mathrm{~g} / 1$ & $\begin{array}{l}560 \mathrm{~nm}=0,453 \\
380 \mathrm{~nm}=0,600\end{array}$ & $\begin{array}{l}560 \mathrm{~nm}=0,538 \\
380 \mathrm{~nm}=0,641\end{array}$ \\
\hline F-84h & $24,3 \mathrm{gl}$ & $27,6 \mathrm{~g} / 1$ & $\begin{array}{l}545 \mathrm{~nm}=0,476 \\
380 \mathrm{~nm}=0,615\end{array}$ & $\begin{array}{l}560 \mathrm{~nm}=0,414 \\
380 \mathrm{~nm}=0,556\end{array}$ \\
\hline F-96h & $17 \mathrm{~g} / 1$ & $25 \mathrm{~g} / 1$ & $500 \mathrm{~nm}=0,313$ & $560 \mathrm{~nm}=0,440$ \\
\hline
\end{tabular}




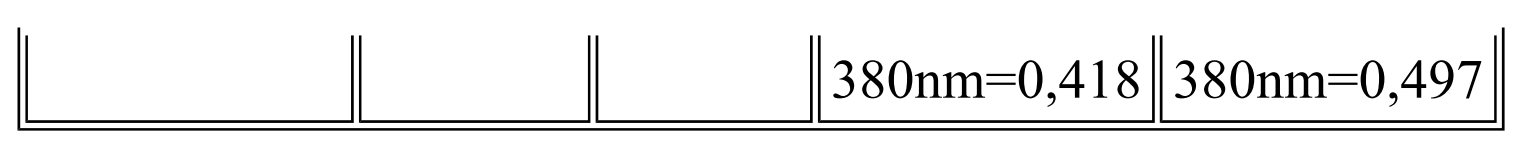

Não se observou produção de esporos nos meios de cultura aqui empregados. Este fato está de acordo com STAVELY \& NIMMO (1968) e BLANEY (1987) que registraram que a esporulação de Cercospora sp in vitro nem sempre tem sido bem sucedida. Embora $C$. caricis seja um agente potencial para o biocontrole de $C$. rotundus, tem crescimento lento e não esporula facilmente em cultura (BARRETO \& EVANS 1995). RIBEIRO et al. (1997), não detectaram esporos de C. caricis (CEN66) nos meios testados, entretanto observaram que sua massa micelial fresca infecta a tiririca .

De acordo com BORGES NETO (1997), C. caricis CEN66 cresceu em alguns meios de cultura, mas não esporulou ou somente esporulou ocasionalmente, produzindo um pouco de esporos em meio EFTA (extrato de folha de tiririca-agar).

Bioensaio: Plantas de tiririca regadas com a solução de $C$. caribaea tiveram algumas folhas amareladas com um mês de inoculação e apresentaram-se completamente secas com três meses e meio após a inoculação. As regadas com a solução de $C$. henningsii, começaram a amarelar progressivamente, em menos de um mês, e tornaramse inteiramente secas em dois meses após terem sido inoculadas com o fungo.

Foi verificado pelo exame feito a olho nú, com lupa e com microscópio ótico a existência de esporos na superfície da lâmina foliar seca dentro da camâra úmida. A olho nú eles se mostraram com uma coloração bem escura ou preta e sob a lupa e ao micróscopio mostraram uma coloração marrom escura. A lâmina foliar quando examinada, já não era hidratada com água por volta de 2 meses. Isso sugere que o fato da morfologia dos conidióforos com os conídios estarem com aspecto mais fino (afilado) comparados àqueles observados em C. caricis (CEN66) por RIBEIRO et al. (1997) se deva a isso. Essa diferença morfológica ainda pode ser devida aos esporos aqui examinados serem de outra espécie que não $C$. caricis. A observação desses esporos comprova a infecção da tiririca (Cyperus sp) por Cercospora sp (C. caribae e/ou $C$. henningsii).

Outro ponto importante, que se pode observar é que Cercospora caricis, $C$. caribaea e C. henningsii desenvolvem-se em meio líquido batata-dextrose (BD), que é um meio barato e de fácil acesso. Dessa forma, estas espécies poderão ser futuros micoherbicidas se houver adicionais estudos de especificidade a esta erva daninha e a plantas não alvo do controle, que são economicamente importantes. O fato de estas três linhagens não produzirem esporos em meio de cultura artificial, não é barreira para a produção de micoherbicidas, visto que testes de infectividade com produtos de $C$. caribaea e $C$. henningsii, sem esporos, confirmaram as observações de BORGES NETO (1997) de que o uso de propágulos frescos, é viável.

MAGALHÃES et al. (1994) ressaltam a importância da produção massal de 
micélio seco como fonte de inóculo, no controle biológico de plantas daninhas.

Os organismos usados como agentes de biocontrole devem ser seguros para o uso no ambiente (FREEMAN \& CHARUDATTAN, 1984).

\section{CONCLUSÕES}

1. Os resultados obtidos demonstraram a possibilidade de produção massal de Bioherbicidas, a partir de microrganismos isolados no país tais como Cercospora henningsii, Cercospora caricis e Cercospora caribaea.

2. Os estudos de fermentação realizados utilizando meios de cultura obtidos com batata (descarte de batatas), mostraram ser este substrato, adicionado de Dextrose, uma boa fonte para o desenvolvimento de Cercospora sp.

3. A temperatura ótima para o desenvolvimento de Cercospora sp foi a $36{ }^{\circ} \mathrm{C}$, ficando o tempo em torno de 72 horas. A $30{ }^{\circ} \mathrm{C}$ o processo demandou um tempo mínimo de 84 horas.

4. Os experimentos realizados em laboratório e campo, com os produtos obtidos contra Cyperus sp, demonstraram a patogenicidade ou seja o potencial bioherbicida de Cercospora sp produzida por fermentação.

5. O experimento em Câmara úmida demonstrou a existência de esporos de Cercospora $s p$ no tubérculo do Cyperus $s p$, preparado e desinfetado após a morte da planta, comprovando que a morte foi causada pela aplicação do produto fermentado.

\section{AGRADECIMENTOS}

À FAPESP pela Bolsa de Mestrado concedida. À Universidade Federal de Pernambuco, Departamento de Micologia, e à CENARGEN/EMBRAPA, pela cessão dos microrganismos.

\section{REFERÊNCIAS BIBLIOGRÁFICAS}

BARRETO, R.W. \& EVANS, H.C. Mycobiota of the weed Cyperus rotundus in the state of Rio de Janeiro, with an elucidation of its associated Puccinia complex. Mycological Research v. 99, n. 4, p. 407- 19, 1995. 
BENDIXEN, L. \& NANDIHALLI, U.B. World Distributiun of purple nutsedge (Cyperus rotundus e Cyperus esculentus). Weed Technology. V. 1, n. 1, p. 61-5, 1987.

BLANEY, C.L., VAN DIKE, C.G. \& GRAND, L.F. Cercospora caricis from Cyperus esculentus (yelow nutsedge): morphology and cercosporin production. Mycologia. v. 80, n. 3, p. 418- 21, 1988.

BORGES NETO, C.R. Estudos sobre Cercospora caricis Ouden. como agente potencial de biocontrole da tiririca (Cyperus rotundus L.). Dissertação (Mestrado ) UnB, Brasília, DF, 1997, 148 p.

CASTELLANI, E. Su die maladie del Cyperus rotundus L. L'Agricoltura Coloniale, v. 20, p. $3-7,1942$.

CHARUDATTAN, R. The mycoherbicide approach with plant pathogens. In: TEBEEST, D. O. (Ed.). Microbial control of weeds. NY, Chapman \& Hall, p. 24 $57,1991$.

EVANS, R.C. Biological control of weeds using fungal pathogens. In Fundamental and applied aspects of invertebrate pathogens. Ed Sanson, R. A., Wlak, J. M., Peters \& Looyen Graphic, The Netherlands. p. 121, 1986.

FREEMAN, T.E. \& CHARUDATTAN, R. Cercospora rodmanii Conway a biocontrol agent for waterhyacinth.. Bulletin 842 (technical). Agricultural Experiment Station, Institute of Food and Agricultural Sciences, University of Flórida, Gainesville, 1984, $112 \mathrm{p}$.

FUSTAÍNO, M.L. \& ORSI, F. Jr. Avanços tecnológicos no manejo de plantas daninhas. In Livro de palestras e mesas redondas do XXI Congresso Brasileiro da Ciência das Plantas Daninhas, Caxambú, MG, p. 189, 1997.

GONZALEZ, C. B.. Estudos de Fermentação submersa para produção massal de um bioherbicida de Cercospora sp contra Cyperus sp (tiririca). Dissertação (Mestrado em Biotecnologia), Instituto de Química., Unesp, Araraquara, SP, 1998, 110 p.

HASAN, S. Plant pathogens and biological control of weeds. Review of Plant Pathology n.59, p. 349-56, 1980.

JOLY, A.B. BOTÂNICA: Introdução à taxonomia vegetal. São Paulo: Companhia Editora Nacional - Editora da Universidade de São Paulo, 1975, 296 p.

LORENZI, H.. Plantas daninhas do Brasil: terrestres, aquáticas, parasitas, tóxicas e medicinais. S. Paulo, Nova Odessa: Editora Plantarum. 2. Ed., 1991 
MAGAlHÃES, B. P., DIAS, S. C. M. de S. \& FERREIRA, C. M. Mycelial production of Metarhizium anisopliae in liquid culture, using different souces of carbon and nitrogen. Rev. Microbiol. São Paulo, v. 25, n. 3, p 181-7, 1994.

MORAES, I. O.; CAPALBO, D. M. F. \& MORAES, R. O. Multiplicação de agentes de Controle Biológico. In: Controle Biológico de doenças de plantas. Ed. W. Bettiol, Jaguariuna, S.Paulo: editora EMBRAPA-CNPDA v. 17 p.253-72, 1991.

PHATAK, S.C., SUMMER, D.R., WELLS, H.D., BELL, D.K. and GLAZE, N.C. Biological control of yellow nutsedge with the indigenous rust fungus Puccina canaliculata. Science n. 219, p. 1446-7, 1983.

RAVEN, P.H., EVERT, R.F. \& CURTIS, H. Biologia Vegetal.. Rio de Janeiro: Editora Guanabara, 2 ed, 1978, 724 p.

RIBEIRO, Z. M.A., MELLO, S.C. M.M., FURLANETTO, C., FIGUEIREDO, G. \& FONTES, E.M.G. Characteristics of Cercospora caricis, a potential biocontrol agente of Cyperus rotundus. Fitopatologia brasileira v. 22, n. 4, p. 513-9, 1997.

STAVELY, R. J. \& NIMMO, J.A. Relation and Nutrition to growth and sporulation of Cercospora nicotinae. Phytopathology n. 58, p. 1372-6, 1968.

STOVAL, M.E. \& CLAY, K. The effect of the fungus, Balansia cyperi Edg., on growth and reproduction of the purple nutsedge, Cyperus rotundus L. New Phytopatologist, v.109, n. 3, p. 351-9, 1988.

TEBEEST, D.E. \& TEBEEST, C.E. Mycoherbicide: progress in the biological control of weeds. Plant disease n.69, p. 6-10, 1985.

TEBEEST, D.E., YANG, X.B. \& CISAR, C. R. The status of biological control of weeds with fungal pathogens. Annu. Ver. Phytopathol., n.30, p. 637 - 57, 1992.

TEBEEST, D.E., TEBEEST, C.E \& SMITH, R.J. Biological weed control with mycoherbicides. Annu. Rev. Phytopathol. n.17, p. 301-10, 1979.

UPADHAYAY, R.K. \& STROBEL, G.A. Phoma cyperi sp. nov., a new pathogen of Cyperus iria, its vegetative and reproductive structures and production of phytotoxins. Can. J. Bot. , n. 68, p. 2059-64, 1990.

UPADHAYAY, R.K., KENFIELD, D., STROBEL, G.A. \& HESS, W.M. Ascochita cypericola sp. nov. causing leaf blight of purple nutsedge (Cyperus rotundus). Can J. Bot. n. 69, p. 797 - 802, 1991.

WETZSTEIN, H.Y. \& PHATAK, S.C. Scaning electron microscopy of the uredinal Stage of Puccinia canaliculata on yellow nutsedge, Cyperus esculentus 
(Cyperaceae). Amer. Bot. v. 74, n. 1, p. 100- 6, 1987.

WILSON, C.L. Use of plant pathogens in weed control. Ann. Rev. Phytopathol. n. 7, p. 411- 4, 1969. 